\title{
Spontaneous Regression Rate of Low Grade Cervical Intraepithelial Lesions Diagnosed from Colposcopy
}

Warangkana Apiwattanasevee, M.D., Nida Jareemit, M.D., Boonlert Viriyapak, M.D.

Division of Gynecologic Oncology, Department of Obstetrics and Gynecology, Faculty of Medicine Siriraj Hospital, Mahidol University, Bangkoknoi, Bangkok 10700, Thailand.

Received 2 May 2018 • Accepted 6 June 2018 • Published online 20 August 2018

\section{Abstract:}

Objective: To evaluate the spontaneous regression rate and its associated factors of low grade intraepithelial lesions after colposcopy in Thai women.

Material and Methods: A retrospective study of the data of Thai women, not younger than 21 years old with liquidbased cervical cytology of atypical squamous cells of undetermined significance (ASC-US) or low-grade squamous intraepithelial lesions (LSIL), who had received colposcopic examination with histologically proven cervical intraepithelial neoplasia grade 1 (CIN1) or human papillomavirus (HPV) infection. All patients underwent cytologic tests as the follow-up method for at least 2 years at the Gynecology Clinic, Siriraj Hospital. Analyzed data included patient characteristics, cervical cytological and pathological results, colposcopic findings and evidence of cytological regression. The correlations between each variable and regression status were then measured.

Results: Data of a total of 154 patients who completed 2 years of follow-up were reviewed. One hundred and two patients had cytologic regression, showing a regression rate of $66.2 \%$. There was $31.8 \%$ persistent abnormal cytology, and $2.0 \%$ progressed to high-grade cervical intraepithelial lesions. All patients with persistence or progression of cervical cytology had no invasive lesion. The only factor significantly related to cytologic regression was the pattern of colposcopic findings ( $p$-value $=0.041$ ). The HPV-specific lesion on the colposcopy showed the significant pattern with an odds ratio of 3.5 (95\% confidence interval $=1.2-10.1, p$-value $=0.028)$.

Conclusion: Women who had initial cervical cytology of ASC-US or LSIL with colposcopic histological confirmation of CIN1 or HPV infection had spontaneous regression, about two-thirds within 2 years of follow-up time. Thus, conservative management in these patients should be considered.

Keywords: ASC-US, CIN1, colposcopy, LSIL, spontaneous regression 


\section{Introduction}

Cervical cancer is the fourth most common global cancer in females and also one of the main health problems in Thailand. ${ }^{1,2}$ Persistent infection of human papillomavirus (HPV) is the cause of cervical cancer and precancerous cervical lesions. Specifically, women infected with oncogenic HPV tend to have longer periods of persistent cervical intraepithelial neoplasia (CIN), consistently named as squamous intraepithelial lesion (SIL), and shorter progressions to cancer than those who had non-oncogenic infections. ${ }^{3}$ However, the low-grade cervical intraepithelial lesions, which include persistent HPV infection and cervical intraepithelial neoplasia grade 1 (CIN1), frequently show slow progression and often remission. ${ }^{4}$ In a clinical setting, balance between the adequate follow-up for spontaneous regression and early treatment with the subsequent risk of procedure-related cervical morbidities for secondary prevention of cervical cancer are still problematic.

Previous studies found that more than $90.0 \%$ of CIN1 would spontaneously resolve within 2 years. ${ }^{5,6}$ Similarly, the low-grade cervical lesions on colposcopy had a tendency to progress about $10.0 \% .^{6,7}$ In addition, $90.0 \%$ of young women (age $<30$ years) who had an HPV infection recovered from the lesions themselves within 3 years. ${ }^{8}$ In contrast, some studies show that the patients with low-grade abnormal cervical cytology with normal colposcopic findings had a risk of high-grade lesions, $1.3-8.5 \%$ after 5 years of followup. $^{9,10}$ Thus, a high regression rate should warrant the postponement of any treatment for CIN1 for 2 years. This was confirmed by the 2012 American Society for Colposcopy and Cervical Pathology (ASCCP) consensus guidelines. ${ }^{5}$

According to the data about the progression of the disease: the disease factors which are oncogenic types of HPV and numbers of viral load or patient factors, such as smoking, multiparity, history of abortion and multiple partners, were associated with the progression of low-grade CIN to high-grade CIN or more. ${ }^{11-14}$ Condom use reduced HPV transmission and promoted the regression of $\mathrm{CIN}^{14}$

In Thailand, the study of Poomtavorn et al. revealed that the incidence of cytologic abnormalities at the 12-month follow-up in patients identified with CIN1 who underwent cryotherapy or expectant management were similar, 19.2\% vs $16.1 \%$ respectively. ${ }^{15}$ Nevertheless, this study had only 12 months of follow-up data and did not determine the factors related to the regression rate of $\mathrm{CIN1}{ }^{15}$ Hence, the aim of our study was to determine the natural course of CIN1, including HPV infection in regression, persistence and progression up to 24 months of follow-up, as well as the factors associated with the regression rate.

\section{Material and Methods}

This retrospective study was conducted using the medical records of the women who visited the Colposcopy Clinic, Department of Obstetrics and Gynecology, Faculty of Medicine Siriraj Hospital, Bangkok, Thailand from January 2007 till November 2013, with the approval of the Ethics Committee of the Faculty of Medicine, Siriraj Hospital, Mahidol University (COA no. Si071/2016).

Eligible data were obtained from Thai women aged equal or older than 21 years with cervical cytology of atypical squamous cells of undetermined significance (ASC-US), LSIL together with histologically confirmed CIN1 or HPV infection on colposcopic examination with cervical tissue biopsy or endocervical curettage.

Exclusion criteria were women who had prior history of abnormal cervical cytology, previous treatment for cervical intraepithelial lesions or cervical cancer, known human immunodeficiency virus (HIV) infection or pregnancy. Inconclusive subjects due to lack of follow-up data or intervening surgical procedures were also not eligible. Subjects with lost follow-up cervical cytology data or limited follow-up duration, less than 2 years, were also excluded. 
The collected data included characteristic data, cervical cytology, colposcopic findings, histopathological results and cytologic follow-up data. In our single institute study, all diagnostic procedures were standardized in the studied population. Cervical cytology is a well validated liquid based cytology, ${ }^{16-18}$ devised by the Faculty of Medicine, Siriraj Hospital, using the 2014 Bethesda system. Diagnostic colposcopy was performed by experienced colposcopists using the modified Reid colposcopic index. The histology was originally reported by gynecologic pathologists, according to the World Health Organization (WHO) classification of tumors of female reproductive organs. Endocervical curettage was usually recommended in cases of only HPVspecific lesions or no visible lesion on the colposcopy. There was no modification of the follow-up strategy in patients who received HPV vaccine during the study. Lesions were defined as HPV-specific when colposcopic findings indicated HPV infections such as Condyloma acuminata or surface spicules. Within 2 years of diagnosis, regression was defined as at least 2 consecutive negative cervical cytology results at least 6 months apart. ${ }^{20-22}$ Persistence was mentioned when an HPV (ASC-US or LSIL) persisted during the follow-up period. The definition of progression was any change to a higher grade cervical cytology than LSIL following cervical cytology. Through the $1^{\text {st }}$ and $2^{\text {nd }}$ years of follow-up, cervical cytology was performed every 6 months. If the patients had any cytologic progression, they received diagnostic colposcopy. At the $2^{\text {nd }}$ year followup, the patients who had persistence or progression of abnormal cervical cytology were reevaluated with colposcopy to confirm diagnosis and tailor treatment. Also, in case of a persistent abnormal cytology of longer than 24 months, colposcopy would be considered for reassessment.

The sample size was calculated from a $90.0 \%$ regression rate of low-grade cervical intraepithelial lesions, according to the previous studies. ${ }^{5,6}$ Regarding 5\% absolute precision and $95 \%$ confidence level, after calculations estimating an infinite population proportion, plus adding $10.0 \%$ for data variation, the total sample size was 154 patients.

Statistical analysis was performed using the Statistical for the Social Science for windows version 21. All quantitative data are displayed as mean and standard deviation. Qualitative data are noted as a number and percentage. Comparative data were analyzed using independent sample t-test, chi-square test or Fisher exact test and 95\% confidence interval $(\mathrm{Cl})$. Kaplan Meier and logistic regression models were used in time-to-event data analysis. P-value $<0.05$ was considered statistically significant in this study.

\section{Results}

All 161 cases were reviewed. With the exclusion of 7 patients who were treated surgically during the study period, including 5 patients immediately treated after diagnosis and another 2 patients, 1 with persistence and another with progression, who were both treated before completing the expected 2 years of follow-up, a total of 154 patients were finally analyzed. With a conservative strategy, the patients' courses of disease were followed as mentioned in Table 1. The overall regression rate and the follow-up period are summarized in Figure 1. Along with the 2 years of follow-up data after diagnosis of low-grade cervical lesions with prior low grade cytology, it was found that only $22.7 \%$ of the patients experienced cytologic regression in the first year while the regression rate increased to $66.2 \%$ after 2 years of follow-up. Persistent abnormal cytology was rated as $77.3 \%$ and $31.8 \%$ at the completion of the $1^{\text {st }}$ and $2^{\text {nd }}$ year of follow-up, respectively. In this review, we found only 3 patients with progression (2.0\%), revealing either that cytologic progression to atypical squamous cells cannot exclude HSIL (ASC-H) or high-grade squamous intraepithelial lesions (HSIL) at the completion of the $2^{\text {nd }}$ year of follow-up. All 3 patients were reevaluated by colpo- 
scopy and specifically treated using the therapeutic loop electrosurgical excision procedure (LEEP) with histological confirmation of HSIL. Fortunately, no progression to invasive carcinoma was demonstrated in this study.

Table 1 Outcomes of patients after follow-up

\begin{tabular}{lll}
\hline & $\begin{array}{l}\text { At 1 year } \\
\text { Number }(\%)\end{array}$ & $\begin{array}{l}\text { At 2 years } \\
\text { Number (\%) }\end{array}$ \\
\hline Regression & $35(22.7)$ & $102(66.2)$ \\
Persistence & $119(77.3)$ & $49(31.8)$ \\
Progression & $0(0.0)$ & $3(2.0)$ \\
\hline Total & $154(100.0)$ & $154(100.0)$ \\
\hline
\end{tabular}

The baseline characteristics are displayed in Table 2. After the completion of 2 years of follow-up, analyzed patients were divided into 2 groups according to the disease course outcomes: the regression group contained 102 patients (66.2\%) and the non-regression group included 52 patients (33.8\%) with persistence or progression. There was no significant difference in ages, body mass index (BMI), parity, abortion history, age at the time of first intercourse, number of lifetime partners, menopausal status, contraception, history of sexually transmitted disease, comorbidity and history of HPV vaccination. Furthermore, the initial cytology and pathology, previous normal cytology, and HPV testing results were also not significantly associated between the two groups.

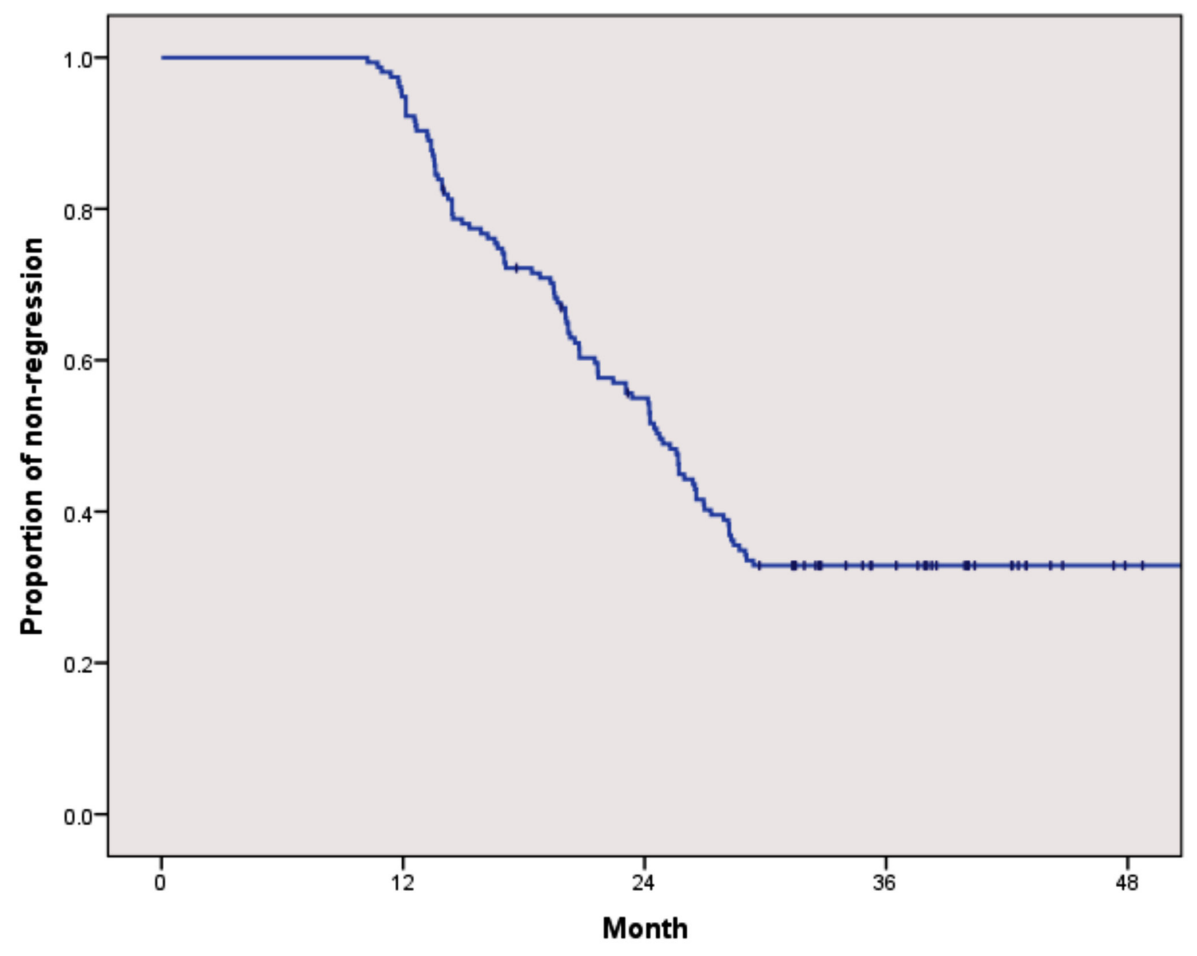

Figure 1 Time to regression 
Table 2 Initial baseline characteristics of patients

\begin{tabular}{|c|c|c|c|}
\hline Patient characteristics & $\begin{array}{l}\text { Regression } \\
\text { Number }=102\end{array}$ & $\begin{array}{l}\text { Non-regression } \\
\text { Number }=52\end{array}$ & P-value \\
\hline & \multicolumn{2}{|c|}{ (Means \pm S.D. $)^{*}$} & \\
\hline Age (year) & $39.4 \pm 9.9$ & $38.2 \pm 10.5$ & 0.457 \\
\hline $\mathrm{BMI}\left(\mathrm{kg} / \mathrm{m}^{2}\right)$ & $22.3 \pm 4.2$ & $22.6 \pm 4.9$ & 0.740 \\
\hline Parity & $1.0 \pm 1.1$ & $1.0 \pm 1.1$ & 0.752 \\
\hline Abortion & $0.2 \pm 0.6$ & $0.2 \pm 0.4$ & 0.625 \\
\hline Age at $1^{\text {st }}$ intercourse (year) & $22.9 \pm 5.2$ & $21.8 \pm 3.8$ & 0.310 \\
\hline \multirow[t]{2}{*}{ No. of lifetime partners } & $1.7 \pm 1.4$ & $2.1 \pm 1.4$ & 0.190 \\
\hline & \multicolumn{2}{|c|}{ Number $(\%)^{\#}$} & \\
\hline \multicolumn{4}{|l|}{ Menopausal status } \\
\hline Premenopause & $80(78.4)$ & $45(86.5)$ & 0.224 \\
\hline Postmenopause & $22(21.6)$ & $7(13.5)$ & \\
\hline \multicolumn{4}{|l|}{ Contraception } \\
\hline None & 39 (38.2) & $11(21.6)$ & 0.207 \\
\hline $\mathrm{OC}$ & $22(21.6)$ & $15(29.4)$ & \\
\hline DMPA & $5(4.9)$ & $1(2.0)$ & \\
\hline Implant & $0(0.0)$ & $2(3.9)$ & \\
\hline IUD & $4(3.9)$ & $3(5.9)$ & \\
\hline Condom & $15(14.7)$ & $8(15.7)$ & \\
\hline Tubal sterilization & $15(14.7)$ & $11(19.6)$ & \\
\hline Withdrawal method & $2(2.0)$ & $1(1.9)$ & \\
\hline \multicolumn{4}{|l|}{ Sexual transmitted disease } \\
\hline None & $100(98.0)$ & $51(98.1)$ & 0.395 \\
\hline Condyloma acuminata & $0(0.0)$ & $1(1.9)$ & \\
\hline Trichomoniasis & $1(1.0)$ & $0(0.0)$ & \\
\hline Herpes genitalia & $1(1.0)$ & $0(0.0)$ & \\
\hline \multicolumn{4}{|l|}{ Comorbidity } \\
\hline None & $84(82.3)$ & $42(80.8)$ & 0.531 \\
\hline Diabetes mellitus & $2(2.0)$ & $3(5.8)$ & \\
\hline Hypertension & $5(4.9)$ & $1(1.9)$ & \\
\hline Dyslipidemia & $2(2.0)$ & $0(0.0)$ & \\
\hline Kidney disease & $1(1.0)$ & $1(1.9)$ & \\
\hline Autoimmune disease & $1(1.0)$ & $2(3.8)$ & \\
\hline Others & $7(6.8)$ & $3(5.8)$ & \\
\hline
\end{tabular}


Table 2 (continued)

\begin{tabular}{|c|c|c|c|}
\hline Patient characteristics & $\begin{array}{l}\text { Regression } \\
\text { Number }=102\end{array}$ & $\begin{array}{l}\text { Non-regression } \\
\text { Number }=52\end{array}$ & P-value \\
\hline & \multicolumn{2}{|c|}{ Number $(\%)^{\#}$} & \\
\hline \multicolumn{4}{|l|}{ Smoking } \\
\hline None & $99(97.1)$ & $50(96.2)$ & 1.000 \\
\hline Smoking & $3(2.9)$ & $2(3.8)$ & \\
\hline \multicolumn{4}{|l|}{ HPV vaccination } \\
\hline None & 95 (93.2) & $47(90.4)$ & 0.177 \\
\hline \multicolumn{4}{|l|}{ Vaccination } \\
\hline Bivalent vaccine & $3(2.9)$ & $0(0.0)$ & \\
\hline Quadrivalent vaccine & $4(3.9)$ & $5(9.6)$ & \\
\hline \multicolumn{4}{|l|}{ Initial Cervical cytology } \\
\hline ASC-US & $36(35.3)$ & $19(36.5)$ & 0.879 \\
\hline LSIL & $66(64.7)$ & $33(63.5)$ & \\
\hline \multicolumn{4}{|l|}{ Initial Pathological result ${ }^{+}$} \\
\hline HPV infection & $53(52.0)$ & $28(53.8)$ & 0.825 \\
\hline CIN1 & $49(48.0)$ & $24(46.2)$ & \\
\hline \multicolumn{4}{|l|}{ Initial Colposcopic diagnosis } \\
\hline Normal & $12(12.0)$ & $12(22.2)$ & 0.061 \\
\hline HPV infection & 35 (34.3) & $10(19.2)$ & \\
\hline LSIL & $55(53.7)$ & $30(58.6)$ & \\
\hline \multicolumn{4}{|l|}{ Previous cytologic screening } \\
\hline None & $53(52.0)$ & $28(53.8)$ & 0.825 \\
\hline Yes & $49(48.0)$ & $24(46.2)$ & \\
\hline \multicolumn{4}{|l|}{ HPV testing } \\
\hline None & $84(82.3)$ & $38(73.1)$ & 0.370 \\
\hline \multicolumn{4}{|l|}{ Yes } \\
\hline Negative for high risk HPV & $4(3.9)$ & $4(7.7)$ & \\
\hline Positive for high risk HPV & $14(13.8)$ & $10(19.2)$ & \\
\hline
\end{tabular}

*Independent sample t-test, ${ }^{~}$ Chi-square test or Fisher exact test, ${ }^{+}$Derived from cervical biopsy or endocervical curettage $-\mathrm{OC}=$ oral contraception, DMPA=depomedroxyprogesterone acetate, IUD=intrauterine device, HPV=human papilloma virus, S.D.=standard deviation, BMI=body mass index, ASCUS=atypical squamous cells of undetermined significance, LSIL=low-grade squamous intraepitheliall esions, $\mathrm{CIN}=$ cervical intraepithelial neoplasia 
According to the initial colposcopic findings as shown in Table 3, it was demonstrated that 24 patients with an $80.0 \%$ satisfactory rate had no mentionable lesion on colposcopy, which included 12 patients (11.8\%) in the group of regressions and 12 patients $(23.1 \%)$ in the nonregressed group. Mainly with the colposcopic lesions, we stressed the significant abnormalities as HPV-specific lesion, acetowhite lesion or a combination of both typical lesions, and it was found that there was a significant difference in the mentioned patterns of colposcopic lesions between the 2 groups ( $p$-value=0.041). On the other hand, the data of colposcopic adequacy, type of transformation zone, surface extent of lesion, distribution of lesion, quadrant of main lesion and existing lesions, such as punctation, mosaicism or abnormal vessels, could not demonstrate any significant difference in the comparison of these patient groups.

The predictive variables of regression were calculated by logistic regression analysis and are displayed in Table 4. When compared with no detectable lesion on initial colposcopic examination, HPV-specific lesion was the sole factor significantly related to the regression. It increased the rate of regression with an odds ratio of 3.5 (95\% $\mathrm{Cl}=1.2-10.1$, $p$-value $=0.028$ ), whereas the patterns of acetowhite lesion or combined acetowhite and HPV-specific lesions showed no significant relevance.

Table 3 Initial colposcopic evaluation

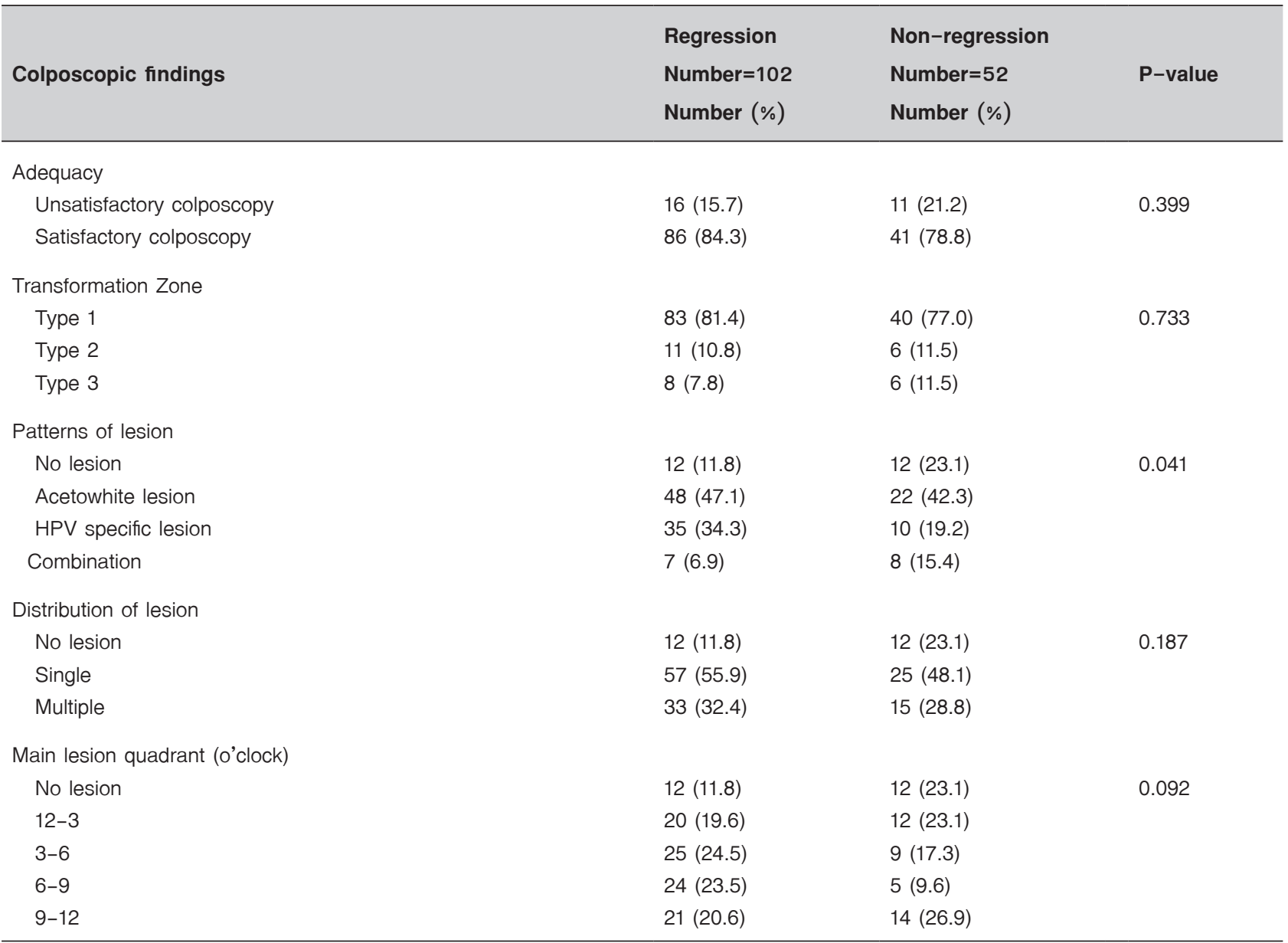


Table 3 (continued)

\begin{tabular}{|c|c|c|c|}
\hline \multirow{3}{*}{ Colposcopic findings } & Regression & Non-regression & \multirow{3}{*}{ P-value } \\
\hline & Number $=102$ & Number $=52$ & \\
\hline & Number (\%) & Number (\%) & \\
\hline \multicolumn{4}{|c|}{ Surface extent of lesion (\%) } \\
\hline No lesion & $12(11.8)$ & $12(23.1)$ & 0.145 \\
\hline $1-25$ & $55(53.9)$ & $27(52.0)$ & \\
\hline $26-50$ & $22(21.6)$ & $6(11.5)$ & \\
\hline $51-75$ & $6(5.9)$ & $1(1.9)$ & \\
\hline $75-100$ & $7(6.8)$ & $6(11.5)$ & \\
\hline \multicolumn{4}{|l|}{ Punctation pattern } \\
\hline None & $82(80.4)$ & $42(80.8)$ & 0.955 \\
\hline Yes & $20(19.6)$ & $10(19.2)$ & \\
\hline \multicolumn{4}{|l|}{ Mosaic pattern } \\
\hline None & $97(95.1)$ & $47(90.4)$ & 0.307 \\
\hline Yes & $5(4.9)$ & $5(9.6)$ & \\
\hline \multicolumn{4}{|l|}{ Atypical vessels } \\
\hline None & $102(100.0)$ & $51(98.1)$ & 0.338 \\
\hline Yes & $0(0.0)$ & $1(1.9)$ & \\
\hline
\end{tabular}

Table 4 Predictive variables of regression

\begin{tabular}{llll}
\hline Type of initial colposcopic lesion & Odd ratio & 95\% Cl & P-value \\
\hline No lesion & 1.0 & & Reference \\
Acetowhite lesion & 2.0 & $0.8-5.3$ & 0.132 \\
HPV specific lesion & 3.5 & $1.2-10.1$ & 0.028 \\
Combination & 0.8 & $0.2-3.1$ & 0.839 \\
\hline
\end{tabular}

$\mathrm{Cl}=$ confidence interval, $\mathrm{HPV}=$ human papilloma virus

\section{Discussion}

In the past, treatment of CIN1 or cervical persistent HPV infection was individualized. After plenty of previous studies showing high rates of spontaneous regression, up to $90.0 \%$ in 2 years, the 2012 ASCCP consensus guidelines enhanced the follow-up strategy in these patients without any surgical procedure. ${ }^{5}$ In Thailand, where a routine cervical cancer screening system using combined cervical cytology and HPV-Deoxyribonucleic acid (DNA) testing has not been well established, the screening and follow-up method using Pap smear were generally applied. Confirmed colposcopy and biopsy were recommended in order to correctly diagnose and support the conservative approach. 
Although our study revealed a $66.2 \%$ regression rate after a 2-year follow-up, which is less than the estimated $90.0 \%$ rate in other studies, ${ }^{5,6,21}$ it strikingly increased from only the $22.7 \%$ level at the $1^{\text {st }}$ year followup. According to these findings, the authors encourage a longer follow-up of 24 months in accordance with the 2012 ASCCP consensus guidelines. We propose performing a reassessed colposcopy in case of any cytologic progression or cytologic persistence longer than 1 year in order to confirm that those patients are not at the high-grade cervical intraepithelial lesion stage, and continue conservative management. Furthermore, our data showed that most of the patients with persistent disease after a 24-month follow-up had been reevaluated and treated without any invasive progression. Therefore, a longer follow-up strategy would be optional in cases of patients who had confirmed persistent low-grade disease, and needed conservative management with good compliance.

However, our lower regression rate corresponded to a large review of data by Oster in 1993, which revealed a summarized regression rate of $57.0 \%{ }^{23}$ This might be explained by the fact that data from many previous studies used different sensitivity tests and different follow-up intervals to detect cervical abnormalities, and thus demonstrated more diseases and less regression. Regarding the higher regression rates from recent studies, a higher specificity diagnostic tool, a histologically proven method, would affect the disease detection and the regression. To make a certain comparison of spontaneous regression, the gold standard of diagnosis using histological approval should be decided. ${ }^{24}$

Nevertheless, in our setting, only 32 patients (20.8\%) underwent HPV testing at the diagnostic and follow-up events. Although oncogenic HPV infection is a strong risk factor for CIN progression in many studies, ${ }^{3,11-14,19}$ this limited test would have resulted in no difference comparatively between the groups in our report.
According to a nationwide cohort study in Sweden of women with a significant risk of cervical cancer, colposcopic examination was recommended to patients aged 28 years or older with ASC-US and LSIL. ${ }^{20}$ We also considered colposcopy as an assessment tool with the availability of accurate biopsy for histologically confirmed diagnosis. Interestingly, the pattern of colposcopic lesions was the single factor that significantly influenced the disease regression. In detail, it was the HPV-specific lesion that was significantly related to regression, with a 3.5 times higher likelihood. The reason is that manifest HPV lesions represented not only a persistent HPV infection, but also transient HPV lesions probably caused by non-oncogenic HPV; thus regression frequently occurred later. Other patterns of lesions, such as acetowhite or even no detectable lesion, might contain occult dysplastic lesions at both the detected acetowhite area and invisible endocervical canal.

The strength of this study is not only that it confirms a high spontaneous cytologic regression rate of low-grade cervical lesions, but also due to it being the first report to explain the relation between colposcopic evaluation and regression. The main drawback of this study is its lack of histologic diagnosis at the 1 and 2-year follow-up. Our retrospective design is also a limitation, due to the selection of conservatively managed subjects. In addition, non-unique assessment tools and inhomogeneous followup intervals were also causes of inconsistent data.

In summary, this data encourages a reasonable 2-year surveillance of women who have CIN1 or HPV infection after colposcopic biopsy in accordance with the 2012 ASCCP consensus guidelines. A colposcopic examination showing HPV-specific lesions would help to ensure a higher relation to regression than other findings. This information could enhance both physician and patient understanding and acceptance of the conservative management plan, which would restrict the morbidities from any 
premature treatment. About one-third of the patients revealed persistent abnormal cytology after 2 years of follow-up; thus, a colposcopic reevaluation with tissue biopsy should be performed in order to decide on a specific treatment for the progression and to adjust for proper management in the follow-up period for persistence.

\section{Conclusion}

After 2 years of follow-up, the majority of women who had histologic confirmation of CIN1 or HPV infection with prior cytology of ASC-US or LSIL spontaneously regressed, thus warranting the value of the conservative approach. Without other risk factors, the colposcopic finding of an HPV-specific lesion was a related factor for regression.

\section{Acknowledgement}

The authors appreciate all the gynecologic oncology staff of the Department of Obstetrics and Gynecology, Siriraj Hospital for their helpful suggestions and Mr. Suthipol Udompunturak, a statistician for the Siriraj Medical Research Center, for statistical analyses.

\section{Conflict of interest}

The authors declare no conflict of interest.

\section{References}

1. Ferlay J, Soerjomataram I, Dikshit R, Eser S, Mathers C, Rebelo $\mathrm{M}$, et al. Cancer incidence and mortality worldwide: Sources, methods and major patterns in GLOBOCAN 2012. Int J Cancer 2015;136:359-86.

2. National Cancer Institute, Department of medical services, Ministry of Public Health Thailand. Hospital based cancer register Annual Report 2012. Bangkok: Eastern Printing Public; 2014.

3. Schlecht NF, Platt RW, Duarte-Franco E, Costa MC, Sobrinho $\mathrm{JP}$, Prado JC, et al. Human papillomavirus infection and time to progression and regression of cervical intraepithelial neoplasia. J Natl Cancer Inst 2003;95:1336-43.
4. Wright TC, Ferency AF, Kurman RJ, Precancerous lesions of the cervix. In: Kurman J, editor. Blaustein's Pathology of the Female Genital Tract. $5^{\text {th }}$ ed. New York: Springer Verlag; 2002;p.253-354.

5. Massad LS, Einstein MH, Huh WK, Katki HA, Kinney WK, Schiffman M, et al. 2012 Updated Consensus Guidelines for the Management of Abnormal Cervical Cancer Screening Tests and Cancer Precursors. J Low Genit Tract Dis 2013;17: $1-27$.

6. Cox JT, Schiffman M, Solomon D. Prospective follow-up suggests similar risk of subsequent cervical intraepithelial neoplasia grade 2 or 3 among women with cervical intraepithelial neoplasia grade 1 or negative colposcopy and directed biopsy. Am J Obstet Gynecol 2003;188:1406-12.

7. Katki HA, Gage JC, Schiffman M, Castle PE, Fetterman B, Poitras NE, et al. Follow-up testing post-colposcopy: fiveyear risk of $\mathrm{CIN} 2+$ after a colposcopic diagnosis of CIN1 or less. J Low Genit Tract Dis 2013;17:69-77.

8. Moscicki AB, Shiboski S, Hills NK, Powell KJ, Jay N, Hanson EN, et al. Regression of low-grade squamous intraepithelial lesions in young women. Lancet 2004;364:167883.

9. Smith MC, Keech SE, Perryman K, Soutter WP. A long-term study of women with normal colposcopy after referral with low-grade cytological abnormalities. BJOG 2006;113:1321-8.

10. Guido R, Schiffman M, Solomon D, Burke L. Postcolposcopy management strategies for women referred with low-grade squamous intraepithelial lesions or human papillomavirus DNA-positive atypical squamous cells of undetermined significance: a two-year prospective study. Am J Obstet Gynecol 2003;188:1401-5.

11. Wang PD, Lin RS. Risk factors for cervical intraepithelial neoplasia in Taiwan. Gynecol Oncol 1996;62:10-8.

12. Dalstein V, Riethmuller D, Pretet JL, Carval K, Sautiere JL, Carbillet JP, et al. Persistence and load of high-risk HPV are predictors for development of high-grade cervical lesions: a Iongitudinal French cohort study. Int J Cancer 2003;106: 396-403.

13. Lee $\mathrm{CH}$, Peng CY, Li RN, Chen YC, Tsai HT, Hung YH, et al. Risk evaluation for the development of cervical intraepithelial neoplasia: development and validation of risk-scoring schemes. Int J Cancer 2015;136:340-9. 
14. Ho GY, Kadish AS, Burk RD, Basu J, Palan PR, Mikhail M, et al. HPV-16 and cigarette smoking as risk factors for highgrade cervical intra-epithelial neoplasia. Int J Cancer 1998;78: 281-5.

15. Poomtavorn $Y$, Suwannarurk K, Thaweekul $Y$, Maireang $K$. Cervical cytologic abnormalities of cervical intraepithelial neoplasia 1 treated with cryotherapy and expectant management during the first year follow-up period. Asian Pac $\mathrm{J}$ Cancer Prev 2009;10:665-8.

16. Sangkarat S, Laiwejpithaya S, Rattanachaiyanont M, Chaopotong $\mathrm{P}$, Benjapibal M, Wongtiraporn W, et al. Performance of Siriraj liquid-based cytology: a single center report concerning over 100,000 samples. Asian Pac J Cancer Prev 2014;15:2051-5.

17. Laiwejpithaya S, Benjapibal M, Laiwejpithaya S, Wongtiraporn W, Sangkarat S, Rattanachaiyanont M. Performance and cost analysis of Siriraj liquid-based cytology: a direct-to-vial study. Eur J Obstet Gynecol Reprod Biol 2009;147:201-5.

18. Laiwejpithaya $S$, Rattanachaiyanont M, Benjapibal M, Khuakoonratt N, Boriboonhirunsarn D, Laiwejpithaya S, et al. Comparison between Siriraj liquid-based and conventional cytology for detection of abnormal cervicovaginal smears: a split-sample study. Asian Pac J Cancer Prev 2008; 9:575-80.
19. Hogewoning CJ, Bleeker MC, Brule AJ, Voorhorst FJ, Snijders PJ, Berkhof J, et al. Condom use promotes regression of cervical intraepithelial neoplasia and clearance of human papillomavirus: a randomized clinical trial. Int $\mathrm{J}$ Cancer 2003;107:811-6.

20. Sundstrom K, Lu D, Elfstrom KM, Wang J, Andrae B, Dilner J, et al. Follow-up of women with cervical cytological abnormalities showing atypical squamous cells of undetermined significance or low-grade squamous intraepithelial lesion: a nationwide cohort study. Am J Obstet Gynecol 2017;216:1-15.

21. Lee SS, Collins RJ, Pun TC, Cheng DK, Ngan HY. Conservative treatment of low grade squamous intraepithelial lesions (LSIL) of the cervix. Int J Gynaecol Obstet 1998;60: 35-40.

22. del Pino M, Torne A, Alonso I, Mula R, Masoller N, Fuste V, et al. Colposcopy prediction of progression in human papillomavirus infections with minor cervical lesions. Obstet Gynecol 2010;116:1324-31.

23. Ostor AG. Natural history of cervical intraepithelial neoplasia: a critical review. Int J Gynecol Pathol 1993;12:186-92.

24. Bentley J. Colposcopic management of abnormal cervical cytology and histology. J Obstet Gynaecol Can 2012;34:1188202. 